\title{
CURRÍCULO INTEGRADO E FORMAÇÃO PROFISSIONAL NO PROEJA: Concepções Acerca do Ensino Por Área do Conhecimento
}

\author{
Franciele Fernandes da Silva ${ }^{1}$ \\ Marília Wortmann Marques ${ }^{2}$ \\ Cátia Keske ${ }^{3}$
}

\begin{abstract}
RESUMO
Neste texto discutimos questões que permeiam a formação profissional no Ensino Médio integrado à Educação Profissional, na modalidade Educação de Jovens e Adultos, muito problematizada no campo do direito. Nosso objetivo é descrever e compreender essa oferta no contexto de uma proposta curricular com conhecimentos da formação básica organizados por áreas do conhecimento. Em perspectiva qualitativa, contamos com uma entrevista semiestruturada com jovens e adultos estudantes do Curso Técnico em Edificações Integrado Proeja, do Instituto Federal Farroupilha. Os dados produzidos foram analisados sob as premissas da Análise Textual Discursiva (ATD) e teorizados no entrelaçamento de documentos legais e institucionais sobre a temática, além de autores que discutem a articulação entre educação e trabalho, a formação de professores e os processos de ensino e aprendizagem de jovens e adultos. Nesse contexto metodológico, a premissa elaborada é que os jovens e adultos estudantes do Proeja reconhecem a articulação entre os diferentes saberes que correspondem à formação escolar e ao mundo do trabalho. Nossas compreensões também evidenciam as responsabilidades institucional e docente com a promoção de uma formação integral, o que contribui para a garantia de acesso ao direito à educação, ao trabalho e ao exercício da cidadania.
\end{abstract}

Palavras-chave: Atuação docente. Proeja. Sujeitos jovens e adultos. Educação Básica e Profissional.

\section{INTEGRATED CURRICULUM AND PROFESSIONAL TRAINING IN PROEJA:} CONCEPTIONS ABOUT TEACHING BY AREA OF KNOWLEDGE

\section{ABSTRACT}

In this text, we discuss issues that permeate professional training in High School, integrated with Professional Education, in the modality of Youth and Adult Education. Very problematized in the field of law, our objective is to describe and understand this offer in the context of a curricular proposal with knowledge of basic education organized by areas of knowledge. From a qualitative perspective, we conducted a semi-structured interview with young and adult people from the Building Technical Course integrated to Proeja at Federal Institute Farroupilha. The data produced were analyzed under the premises of the Discursive Textual Analysis (DTA) and theorized on the intertwining of legal and institutional documents on the theme, besides authors who discuss the articulation between education and work, teacher training and the teaching and learning processes of young and adult people. In this methodological context, the premise elaborated is that the young and adult students of PROEJA can recognize the articulation between the different knowledge which correspond to school education and the world of work. Our understanding also highlights institutional and teaching responsibilities with the promotion of integral formation, what contributes to the guarantee of access to the right to education, work and the exercise of citizenship.

Keywords: Teaching practice. Proeja. Young and Adult Subjects. Basic and Professional Education.

Recebido em: $23 / 3 / 2020$

Aceito em: 30/6/2020

\footnotetext{
${ }^{1}$ Mestranda no Programa de Pós-Graduação Stricto Sensu Educação nas Ciências (Universidade Regional do Noroeste do Estado do Rio Grande do Sul - Unijuí). Aluna do Curso de Capacitação em Tradução e Interpretação de Libras da Universidade Tuiuti do Paraná. Graduação em Licenciatura Plena em Ciências Biológicas (Instituto Federal Farroupilha, Campus Panambi). http://lattes.cnpq.br/5353999541284960. https://orcid.org/0000-0002-0630-4326.fran.oly@hotmail.com

2 Graduação em Ciências Biológicas pela Universidade da Região da Campanha (2005). Mestrado em Fitossanidade pela Universidade Federal de Pelotas (2009). Doutorado em Fitopatologia pela Universidade Federal Rural de Pernambuco (2013). Bolsista de Desenvolvimento Científico e Tecnológico Regional (DCR) na Embrapa semiárido. Atua como docente EBTT no Instituto Federal Farroupilha, Campus Panambi. http://lattes.cnpq.br/4031266470116261. https://orcid.org/0000-0001-7505-8395. marilia.marques@iffarroupilha.edu.com

3 Aluna do Programa de Pós-Graduação Stricto Sensu Doutorado em Educação nas Ciências (Universidade Regional do Noroeste do Estado do Rio Grande do Rio Grande do Sul - Unijuí). Graduação em Pedagogia na Unijuí (2006). Especialização em Educação Profissional Integrada à Educação Básica na Modalidade de Educação de Jovens e Adultos pela UFRGS/IF Farroupilha - Campus Júlio de Castilhos (2010). Mestrado em Educação nas Ciências no Programa de Pós-Graduação em Educação na Ciências da Unijuí, bolsista Capes (2011). Tem experiência na área de Educação, com ênfase nas áreas de Formação de Professores, Gestão Educacional e de Educação de Jovens e Adultos. http://lattes.cnpq.br/7898017133637245. https://orcid.org/0000-0002-3700-8634. catia.keske@iffarroupilha.edu.br
} 
A Lei de Diretrizes e Bases da Educação Nacional (LDB) no 9.394/96 estabeleceu dois níveis de Educação escolar: a Educação Básica (que compreende as etapas de Educação Infantil, Ensino Fundamental e Ensino Médio) e o Ensino Superior, cada um deles com suas especificidades e formas de oferta. Uma das modalidades de oferta da Educação Básica é a Educação de Jovens e Adultos (EJA), a qual constitui-se em meio a um processo de contínuas mudanças provocadas por políticas públicas educacionais que, dependendo da proximidade ou do distanciamento de orientações neoliberais, ora promovem e incentivam, ora apenas mantêm o acesso dos jovens e adultos ao saber formal.

Em ambos os níveis e nas diferentes etapas e modalidades, as instituições de ensino brasileiras parecem insistir em não se opor às desigualdades sociais quando desenvolvem suas práticas educativas, mantendo resquícios de um processo excludente. Exclusão esta que fica evidente na EJA que, em síntese, trabalha com sujeitos marginais ao sistema, cujas identidades constituem-se de formas diversas, em meio a condições socioculturais como gênero, classe social e etnia.

Embora a escola seja um espaço de acolhimento, por vezes há situações em que os sujeitos encontram-se em condições desiguais, razão pela qual é importante evidenciá-las para que as políticas públicas sejam (re)elaboradas de forma mais equitativa. Por isso, é essencial a análise de recortes por região e localidade, os quais atentem às diferentes características dos jovens e adultos, tais como mulheres, negros, quilombolas, indígenas, camponeses, ribeirinhos, pescadores, idosos, subempregados, desempregados e trabalhadores informais, emblemáticos representantes das múltiplas apartações que a sociedade brasileira, excludente, promove para grande parte da população desfavorecida econômica, social e culturalmente (BRASIL, 2007).

Nesse contexto de desigualdades socioculturais e de acesso a alguns direitos, como trabalho e educação, a proposição de alternativas que contemplem os sujeitos que compõem a EJA é uma premissa que exige empenho de diferentes esferas sociais, desde políticas educacionais a propostas pedagógicas, perpassando por movimentos sociais em prol de condições de garantir, além do acesso à educação, a permanência e o sucesso escolar. É fundamental, portanto, que uma política pública estável voltada para a EJA contemple a elevação da escolaridade com profissionalização, no sentido de contribuir para a integração sociolaboral desse grande contingente de cidadãos cerceados do direito de concluir a Educação Básica e de ter acesso a uma formação profissional de qualidade (BRASIL, 2007).

Nesse sentido, entre outros espaços, destacam-se os Institutos Federais de Educação, Ciência e Tecnologia (IFs) como promotores de Educação Profissional, de nível médio e superior, com qualidade, pública e gratuitamente. Neste texto descrevemos e analisamos a oferta do Programa Nacional de Integração da Educação Profissional à Educação Básica na Modalidade de Educação de Jovens e Adultos (Proeja) no âmbito de um Instituto Federal, buscando compreender elementos teóricos e pedagógicos do currículo integrado e da formação profissional em uma organização curricular por áreas do conhecimento, a partir de concepções discentes acerca do ensino por área do conhecimento, as quais nos foram possíveis no contexto de uma prática de estágio curricular supervisionado. 


\section{REFERENCIAL TEÓRICO}

\section{PROEJA e Currículo Integrado}

A Lei no 11.892/2008 instituiu a Rede Federal de Educação Profissional, Científica e Tecnológica e criou os Institutos Federais de Educação, Ciência e Tecnologia. Ela instaura uma rede de instituições de ensino com a possibilidade da oferta de Educação Superior, Básica e Profissional, pluricurricular e multicampi, especializada na oferta de Educação Profissional Técnica e Tecnológica nas diferentes modalidades de ensino, bem como na formação de docentes para a Educação Básica (BRASIL, 2008).

Anterior à Lei de criação dos IFs, por meio do Decreto Federal $n^{\circ} 5.840 / 2006$, o Proeja foi instituído com a finalidade de abranger cursos e programas de Educação Profissional de formação inicial e continuada de trabalhadores e também de Educação Profissional técnica de nível médio; trata-se da garantia ao direito à educação básica e à qualificação profissional.

Essa dimensão de garantia a um direito tem sido destacada em pesquisas e estudos acadêmicos, como indicam Paiva, Haddad e Soares (2019). Ao buscar síntese das pesquisas acerca da EJA publicizadas nas reuniões anuais da Associação Nacional de Pós-Graduação e Pesquisa em Educação (Anped) nas últimas quatro décadas, os autores compreenderam que o direito à educação para todos é o fundamento que ancora fortemente esse conjunto de estudos. Segundo eles, reconquistado constitucionalmente em 1988, "esse direito incentiva e promove não apenas ações voltadas ao público jovem e adulto, mas exige também a compreensão de questões relativas ao aprender/escolarizar-se, à formação da cidadania, à luta por direitos conexos e à justiça social" (PAIVA; HADDAD; SOARES, 2019, p. 1).

Arroyo (2017), ao nomear os sujeitos jovens e adultos da EJA como "passageiros da noite", remete intencionalmente a "passageiros do fim da cidade, do fim da linha, do fim dos campos, passageiros dos últimos degraus nas hierarquias de classe, raça, gênero, trabalho, renda, moradia, 'Escolarização'” (ARROYO, 2017, p. 25). Como enfatiza o autor, "os jovens adultos que vêm de trabalhos explorados e fazem seus itinerários para EJA, por que lutam? Apenas por suprir percursos escolares? Lutam por percursos humanos de direitos, por justiça, pela dignidade humana que lhes é roubada" (ARROYO, 2017, p. 93).

Nessa direção, a oferta de cursos nessa modalidade, atendendo uma demanda maior que o direito à educação, isto é, à dignidade humana e à formação da cidadania, pode ser vista a partir das matrículas realizadas. Embora dados quantitativos não nos permitam sozinhos uma análise, vale destacar que, de acordo com o Instituto Nacional de Estudos e Pesquisas Educacionais Anísio Teixeira (Inep), no ano de 2018 foram registradas 48,5 milhões de matrículas nas 181,9 mil escolas de Educação Básica brasileiras, posto que na EJA o número de matrículas chega a 3,5 milhões. Os dados disponibilizados pelo Inep ainda expressam que a EJA é composta predominantemente por alunos com menos de 30 anos, representando $62 \%$ das matrículas e, nessa mesma faixa etária, 
os alunos do sexo masculino são maioria, representando $57,6 \%$ das matrículas. Matrículas acima de 30 anos, entretanto, são predominantemente compostas por estudantes do sexo feminino, representando $58,2 \%$ das matrículas (BRASIL, 2019a).

O Brasil possui, atualmente, 47,9 mil alunos na modalidade EJA integrada à Educação Profissional, sendo 5,7 mil em Nível Fundamental e 42,2 mil em Nível Médio. Esse contingente ainda representa, no entanto, uma pequena parte das matrículas em EJA como um todo. No caso do Ensino Fundamental, a ênfase profissionalizante representa apenas 0,3\% das matrículas, e no Médio somente 2,9\%. 0 ano de 2018 registrou uma queda no número de matrículas na EJA de Ensino Fundamental, na modalidade integrada à Educação Profissional, se comparado a 2017: 51,3\%. Trata-se do menor patamar desde 2009. Na EJA de Ensino Médio, integrada à Educação Profissional, a queda no número de matrículas nos últimos dois anos foi menor em comparação à EJA de Ensino Fundamental dessa modalidade: 1,4\% (BRASIL, 2019b). De acordo com a LDB:

Art. 37. A educação de jovens e adultos será destinada àqueles que não tiveram acesso ou continuidade de estudos nos ensinos fundamental e médio na idade própria e constituirá instrumento para a educação e a aprendizagem ao longo da vida. $\S 1$ O Os sistemas de ensino assegurarão gratuitamente aos jovens e aos adultos, que não puderam efetuar os estudos na idade regular, oportunidades educacionais apropriadas, consideradas as características do alunado, seus interesses, condições de vida e de trabalho, mediante cursos e exames (BRASIL, 2019c).

Dessa forma, o Proeja opera, prioritariamente, na perspectiva de um "projeto político-pedagógico integrado", apesar de ser possível a oferta de cursos de Educação Profissional articulada ao Ensino Médio em outras formas: "integrada, concomitante e subsequente" (BRASIL, 2004), e embora o Decreto no 5.840/2006 preveja, especificamente para o Proeja, as possibilidades de articulação considerando as formas "integrada e concomitante". Na busca de priorizar a integração, os maiores esforços concentram-se em buscar caracterizar a forma integrada, que se traduz por um currículo integrado (BRASIL, 2007). Quando, contudo, se fala em currículo integrado, pergunta-se: Qual o sentido de se integrar o currículo? O que, na verdade, se deseja integrar? E como integrá-lo? (BRASIL, 2007). Por meio das compreensões de Frigotto e Araújo (2015, p. 64),

[..] tomamos a ideia de integração como um princípio pedagógico orientador de práticas formativas focadas na necessidade de desenvolver nas pessoas (crianças, jovens e adultos) a ampliação de sua capacidade de compreensão de sua realidade específica e da relação desta como a totalidade social.

Consoante a isso, os autores defendem o ensino integrado como um projeto que traz um conteúdo político-pedagógico engajado, comprometido com o desenvolvimento de ações formativas integradoras (em oposição às práticas fragmentadoras do saber), capazes de promover a autonomia e ampliar os horizontes (a liberdade) dos sujeitos das práticas pedagógicas, professores e alunos, principalmente (FRIGOTTO; ARAÚJO, 2015).

Tais compreensões permitem-nos entender que o que se pretende é uma integração epistemológica, de conteúdos, de metodologias e de práticas educativas. Em sintonia a essa ideia, o Documento Base do Proeja (BRASIL, 2007) indica que se trata de uma integração entre teoria e prática, entre o saber e o saber-fazer. Em relação ao currículo, 
pode ser traduzido em termos de integração entre uma formação humana mais geral, uma formação para o Ensino Médio e para a formação profissional. Conforme nele expresso,

O currículo integrado é uma possibilidade de inovar pedagogicamente na concepção de ensino médio, em resposta aos diferentes sujeitos sociais para os quais se destina, por meio de uma concepção que considera o mundo do trabalho e que leva em conta os mais diversos saberes produzidos em diferentes espaços sociais. Abandona-se a perspectiva estreita de formação para o mercado de trabalho, para assumir a formação integral dos sujeitos, como forma de compreender e se compreender no mundo (BRASIL, 2007).

No contexto do Instituto Federal Farroupilha (IFFar), o trabalho é concebido como princípio educativo e elemento integrador entre teoria e prática, superando uma perspectiva de preparação para o trabalho reduzida a simples operacionalização de uma tarefa. Busca-se, com isso, perceber a complexidade a que se propõe a proposta de currículo integrado, que visa a oferecer a jovens e adultos o direito a uma educação completa, apropriando-se dos conhecimentos científicos e tecnológicos construídos pela humanidade, incorporando a dimensão intelectual ao trabalho (SANTA MARIA, 2014).

Promover uma formação em Nível Médio e Técnico Integrado implica, nessa perspectiva, uma proposta que pense uma formação humana. Isso impõe ao Proeja a responsabilidade de promover práticas educativas que instiguem e levem os sujeitos jovens e adultos a buscar o acesso ao universo de saberes e conhecimentos científicos e tecnológicos produzidos historicamente pela humanidade, ao mesmo tempo em que vivenciem uma proposta pedagógica de formação profissional que lhes permita compreender o mundo, compreender-se no mundo e nele atuar na busca da melhoria das próprias condições de vida e da construção de uma sociedade socialmente justa (BRASIL, 2007). Ao pensarmos esse conceito de integração, a problematização que emerge é quão distintas são as concepções de integração curricular e de currículo integrado.

Indicando compreensões ao encontro desse desafio, em estudo desenvolvido no contexto do IFFar, Mohr et al. (2016) enfatizam a concepção de que o currículo integrado parte do pressuposto básico de trabalho com a compreensão do real na sua totalidade, podendo, dessa forma, desenvolver os fundamentos das diferentes ciências, aliados aos conhecimentos do mundo do trabalho, sem que isso se constitua numa relação dualista, pelo contrário, constituindo-se em uma relação articulada.

Apoiados nos referenciais supracitados, reconhecemos a distinção entre integração curricular e o currículo integrado, ambos voltados à formação humana e subsidiados pela perspectiva da produção de uma cultura que promova um processo reflexivo, situado no mundo do trabalho, contextualizado histórica e socialmente. Ainda, nos valendo do Documento Base, elaborado ainda em 2007, compreendemos que o que está em questão é "uma política pública de Educação Profissional integrada com a Educação Básica para jovens e adultos como direito, em um projeto nacional de desenvolvimento soberano, frente aos desafios de inclusão social e da globalização econômica" (BRASIL, 2007). 


\section{O Curso de Proeja e o Trabalho por Áreas do Conhecimento}

A oferta de Proeja, bem como toda a oferta de Educação Profissional e Tecnológica no IFFar, se dá em observância à LDB no 9.394/96, em consonância às Diretrizes Curriculares Nacionais para a Educação Profissional Técnica de Nível Médio (BRASIL, 2012) e, em âmbito institucional, às Diretrizes Institucionais da organização administrativo-didático-pedagógica para a Educação Profissional Técnica de Nível Médio (SANTA MARIA, 2014). Institucionalmente, as diretrizes do Plano de Desenvolvimento Institucional (PDI) do IFFar enfatizam a função social de uma formação humanística e integral, na qual os conhecimentos partam da prática social e que a ela retornem, transformando-a (SANTA MARIA, 2019).

Dessa perspectiva de orientações legais e institucionais, podemos afirmar que o Proeja tem a missão de contribuir à formação de cidadãos comprometidos com a realidade social, autônomos, empreendedores e conscientes. Assim, nessa forma de Educação Profissional são contemplados os conteúdos de Formação Técnica e os de Formação Geral, de maneira contextualizada, procurando desenvolver metodologias e práticas educativas integradoras entre teoria e prática e complementadoras do saber-fazer, para um público que há muito tempo não está mais na escola, posto que ficou à margem do sistema escolar.

O currículo do curso Técnico em Edificações Proeja tem como diretriz a formação humana e a formação profissional. Organizado por áreas do conhecimento (Ciências da Natureza e suas Tecnologias, Ciências Humanas e suas Tecnologias, Matemática e suas Tecnologias e Linguagem, Códigos e suas Tecnologias) - organização adotada no período 2014-2019 -, tem o objetivo de integrar a Educação Profissional ao Ensino Médio. Essa oferta propõe desenvolver práticas educativas e institucionais com vistas à formação ética, política e estética para combater as ações que venham reforçar a opressão de uns sobre outros ou degradar a relação do ser humano com a natureza (SANTA MARIA, 2014).

Nesse contexto, interessa-nos destacar o desafio que se constitui a organização do Proeja, pautada pela disposição dos conhecimentos da formação básica de forma sistematizada por áreas do conhecimento. Em síntese, trata-se de promover o maior número de aprendizagens quanto a conhecimentos, de forma a subsidiar as aprendizagens necessárias para que o educando/egresso possa (re)inserir-se (e/ou manter-se) no mundo do trabalho, sem descuidar da formação integral, tampouco desconsiderar que os sujeitos que estão inseridos ou que buscam o Proeja são jovens e adultos.

Para abarcar tais intencionalidades, o curso traz uma proposta de organização curricular embasada na concepção de Currículo Integrado, em uma perspectiva de integração que perpassa todas as dimensões da vida no processo educativo (o trabalho, a ciência e a cultura) (SANTA MARIA, 2014). Propõe, assim, uma organização curricular na qual a formação geral (organizada em áreas de estudo) e a formação técnica sejam interligadas e intercomplementares, buscando superar a visão fragmentada de sujeito e de sociedade produtiva com vistas a ir além da tarefa de preparar sujeitos para trabaIhar (mão de obra), na dicotomia trabalho manual versus trabalho intelectual, alcançando a formação humana integral. 
Sob a intenção de desenvolver práticas curriculares pautadas pela concepção de currículo integrado e atendendo às Diretrizes Curriculares Nacionais para a Educação Profissional Técnica de Nível Médio (BRASIL, 2012), o curso é organizado por meio de três núcleos de formação: Núcleo Básico, Núcleo Politécnico e Núcleo Tecnológico, os quais são perpassados pela Prática Profissional, conforme indicado no Quadro 1.

Quadro 1 - Núcleos de Formação dos Cursos Técnicos Integrados

\begin{tabular}{|c|c|c|}
\hline Núcleo Básico & Núcleo Politécnico & Núcleo Tecnológico \\
\hline $\begin{array}{l}\text { Constituição: } \\
\text { Conhecimentos e habilidades } \\
\text { nas áreas de linguagens e seus } \\
\text { códigos, ciências humanas, ma- } \\
\text { temática e ciências da natureza. } \\
\text { Caracterização: } \\
\text { Tem por objetivo desenvolver } \\
\text { o raciocínio lógico, a argumen- } \\
\text { tação, a capacidade reflexiva, } \\
\text { a autonomia intelectual, con- } \\
\text { tribuindo na constituição de } \\
\text { sujeitos pensantes, capazes de } \\
\text { dialogar com os diferentes con- } \\
\text { ceitos. }\end{array}$ & $\begin{array}{l}\text { Constituição: } \\
\text { Disciplinas que tratam dos co- } \\
\text { nhecimentos e habilidades ine- } \\
\text { rentes à educação básica e téc- } \\
\text { nica, que possuem maior área } \\
\text { de integração com as demais } \\
\text { disciplinas do curso em relação } \\
\text { ao perfil do egresso bem como } \\
\text { as formas de integração. } \\
\text { Caracterização: } \\
\text { Espaço onde se garantem con- } \\
\text { teúdos, formas e métodos res- } \\
\text { ponsáveis por promover, duran- } \\
\text { te todo o itinerário formativo, a } \\
\text { politecnia, a formação integral, } \\
\text { omnilateral, a interdisciplinari- } \\
\text { dade. } \\
\text { Elo comum entre os Núcleos } \\
\text { Básico e Tecnológico. }\end{array}$ & $\begin{array}{l}\text { Constituição: } \\
\text { Disciplinas específicas da } \\
\text { formação técnica, identifi- } \\
\text { cadas a partir do perfil do } \\
\text { egresso, que instrumenta- } \\
\text { lizam domínios intelectuais } \\
\text { definidos no Catálogo Na- } \\
\text { cional dos Cursos Técnicos. } \\
\text { Caracterização: } \\
\text { Espaço da organização cur- } \\
\text { ricular das disciplinas que } \\
\text { tratam dos conhecimen- } \\
\text { tos e habilidades inerentes } \\
\text { à educação técnica e que } \\
\text { possuem maior ênfase tec- } \\
\text { nológica e menor área de } \\
\text { integração com as demais } \\
\text { disciplinas do curso em rela- } \\
\text { ção ao perfil profissional do } \\
\text { egresso. }\end{array}$ \\
\hline
\end{tabular}

Fonte: Adaptado de Santa Maria (2014).

Com carga horária total de 2.400 horas-relógio (1.200 para o Núcleo Básico, 360 para o Núcleo Politécnico e 840 para o Núcleo Tecnológico), o corpo docente, juntamente com os núcleos ligados à Coordenação de Ações Inclusivas e demais setores pedagógicos da instituição, planejam e desenvolvem atividades formativas ao encontro do perfil do egresso e de temáticas transversais e relativas à diversidade e inclusão, a fim de contemplar os conteúdos obrigatórios e atender textos legais bem como às disposições das Diretrizes Institucionais dos Cursos Técnicos. Essas ações são registradas e documentadas no âmbito da coordenação do curso para fins de comprovação (SANTA MARIA, 2014).

Ofertado desde o ano de 2010, foi no período de 2014 a 2019 que o curso de Proeja foi organizado por áreas do conhecimento, sendo antes e posteriormente por disciplinas. É deste período que a forma de organização curricular interessa a este estudo; o curso contempla disciplinas da formação geral (Ciências da Natureza e suas Tecnologias, Ciências Humanas e suas Tecnologias, Matemática e suas Tecnologias e Linguagem, Códigos e suas Tecnologias) do Ensino Médio e disciplinas técnicas específicas, distribuídas durante os três anos de curso. Essa organização - por áreas do conheci- 
mento - exigiu que os docentes organizassem seus planejamentos de forma coletiva, tanto considerando a área de estudo quanto interagindo com a área técnica. Esse é o movimento que se constituiu como condição para a efetiva aplicação dos pressupostos do currículo integrado ao encontro do que autores como Frigotto e Araújo (2015) defendem. Esses encontros coletivos para estudo e planejamento são realizados quinzenal ou mensalmente.

Mesmo a partir de tais encontros e planejamentos, entretanto, há que se considerar o fato de que a carga horária referente ao Núcleo Básico se sobrepõe aos demais. Desse modo, mesmo a partir de uma prática interdisciplinar, o corpo docente e também os alunos têm dificuldade com essa organização. Deve-se atentar, todavia, ao fato de que nenhuma organização igualitária sobre a carga horária dos núcleos pode garantir que se contemple tudo o que é necessário.

\section{METODOLOGIA}

A pesquisa foi desenvolvida no contexto de um curso de formação inicial de professores por um dos campi do IFFar, tendo a problemática sido constatada a partir da realização de um dos estágios obrigatórios. Compreendido como parte das 400 horas de estágio supervisionado previstas em lei para a formação inicial de professores (BRASIL, 2015; BRASIL, 2019d), o Estágio Curricular Supervisionado IV propõe o planejamento e a atuação docente junto a turma de Ensino Médio na disciplina de Biologia, futura área de atuação. Concluído no segundo semestre de 2019, esse estágio ocorreu numa turma de 3 o ano do Ensino Médio do Curso de Proeja e, em meio a essa prática de regência, este estudo foi delineado, suscitado por assuntos abordados pelos jovens e adultos, sujeitos envolvidos, quando compartilhavam questões e problemáticas que permeiam sua realidade.

O percurso metodológico ocorreu por meio de uma pesquisa qualitativa, contando com uma entrevista semiestruturada direcionada aos alunos da turma, no intuito de conhecer os estudantes individual e coletivamente. Participaram da pesquisa todos os alunos da turma. As perguntas foram direcionadas de modo que fosse possível atentar para a idade, gênero, trabalho, escolarização (anterior ao Proeja), tempos de afastamento da escola, fatores de permanência no curso, entre outras questões que permitem analisar o porquê da escolha desses jovens e adultos ao ingressar em um curso do Proeja. Além disso, por meio desse instrumento de produção de dados, foram questionados sobre a integração entre Educação Profissional e Ensino Médio do Curso de Proeja e sua organização por áreas do conhecimento.

A análise dos dados foi realizada sob a perspectiva da Análise Textual Discursiva (ATD) Hermenêutica (SOUZA; GALIAZZI, 2016), a qual, segundo os autores, constitui-se como movimentos interpretativos múltiplos - em espiral e em círculos - para a compreensão profunda e recursiva dos fenômenos sobre os quais se procura construir novos sentidos. Destacam-se aqui dois elementos principais da ATD: 1) unitarização - é parte do esforço hermenêutico de interpretação de textos, em que unitarizar e desconstruir são exercícios que terão sentido quando categorizados; e 2) categorização - possui pressupostos hermenêuticos quando as categorias são descritas e interpretadas, possibilitando maior clareza teórica. 
Sendo a tarefa hermenêutica na ATD o ir além do que já se sabe sobre o fenômeno, aprender sobre ele, ampliando o horizonte interpretativo por meio das emergências teóricas, ou seja, na disposição de novas elaborações dialógicas, buscamos assim fazer, nos deixando provocar pelos encontros textuais que tivemos, tanto na leitura de documentos institucionais e textos legais quanto nos enunciados (mesmo que sucintos) dos jovens e adultos, estudantes do Curso Técnico em Edificações Integrado PROEJA.

Dessa perspectiva, apresentamos a descrição compreensiva que fizemos a partir das três categorias identificadas e que nos levam a um metatexto: 1) Postura do professor e do corpo docente - processo de ensino; 2) processo de aprendizagem do jovem e do adulto; e 3) sobreposição dos conhecimentos da área básica aos da técnica.

\section{ANÁLISE DOS DADOS}

A turma do 3음 ano do curso é composta por 9 alunos, sendo 5 homens e 4 muIheres, com idade entre 20 e 65 anos. Além dessa caracterização inicial, uma das questões que chama atenção é o tempo que os alunos se encontravam fora da escola até sua inserção no Proeja. As respostas variaram, sendo citado que alguns alunos ficaram um curto espaço de tempo - um ano e meio - e outros em torno de seis anos. Outra parte da turma mencionou que já estava fora do ambiente escolar há mais ou menos 20 anos.

No que trata sobre sua escolha ao voltar a estudar, a maioria foi enfática ao afirmar que se deu a partir do desejo de concluir o Ensino Médio e ter uma qualificação profissional, na intenção de conseguir um emprego melhor. Outros pontos, no entanto, foram citados, tais como a exigência do "mercado de trabalho" para sua formação; a busca da formação da área (em casos em que o sujeito já tem experiência e precisa da certificação de seus conhecimentos); e a perspectiva de seguir para o Ensino Superior, ampliando seus conhecimentos na área.

Questionados sobre a escolha de um curso que integra Educação Profissional e geral e, também, os fatores que os fazem permanecer no curso, grande parte citou que sua opção parte do pressuposto de que é um curso integrado, pela formação do Ensino Médio e Técnico juntos. Outro fator citado foi o interesse e gosto pela área de atuação e a intenção de continuar os estudos direcionados a esse campo de trabalho. No que se refere aos fatores de permanência no curso, entre as opções que havia para eles marcarem as mais indicadas foram em relação à qualificação profissional, seguida da qualificação pessoal de cada um, além da qualidade do curso, o incentivo da família, a convivência com os demais e as metodologias utilizadas.

Por fim, ao final do questionário, os alunos tiveram duas perguntas relacionadas ao curso sobre a integração da Educação Profissional ao Ensino Médio e a respeito da organização de o Proeja ser por áreas do conhecimento, cujas respostas resultaram nas categorias definidas a seguir (Quadro 2). Para preservar a identidade dos sujeitos que participaram do questionário, eles foram numerados de 1 a 9, respectivamente. 
Quadro 2 - Categorias emergentes

\begin{tabular}{|l|r|c|}
\hline \multicolumn{1}{|c|}{ Categorias } & Afirmações & Sujeitos \\
\hline $\begin{array}{l}\text { Postura do professor } \\
\text { e do corpo docente - } \\
\text { Processo de ensino }\end{array}$ & $\begin{array}{c}\text { "Bem avaliado, explicado, interativo" } \\
\text { "Interdisciplinar (tudo está relacionado)" }\end{array}$ & $1,2,3,5,6,7,8$ \\
\hline $\begin{array}{l}\text { Processo de } \\
\text { aprendizagem do jovem } \\
\text { e do adulto }\end{array}$ & $\begin{array}{c}\text { "Bom e interessante, dá condições de } \\
\text { melhorar" }\end{array}$ & $2,3,4$ \\
\hline $\begin{array}{l}\text { "Condição de tempo - concluiu dois em um em } \\
\text { menos tempo" } \\
\text { conhecimentos da área } \\
\text { básica e da área técnica. }\end{array}$ & $\begin{array}{c}\text { (Sobreposição) } \\
\text { "Falta de conhecimento na área técnica, menos } \\
\text { hora-aula" }\end{array}$ & $5,9,7$ \\
(Justaposição) & $\begin{array}{c}\text { "Todas as matérias são importantes" } \\
\text { "Espaço de conhecimento" } \\
\text { "Boa distribuição, proporciona bom } \\
\text { conhecimento de ambos" }\end{array}$ & \\
\hline
\end{tabular}

Fonte: Autoria própria (2019).

\section{Postura do Professor e do Corpo Docente - Processo de Ensino}

A sala de aula é alicerçada na heterogeneidade de seus sujeitos, o que se constitui desafio contínuo para o professor atuar. Por vezes, é necessário inovar em cada aula, torná-la "interativa", propondo-a de forma criativa e dialógica. Essa postura docente abre espaço para que outras formas de organização dos processos de ensino e aprendizagem ocorram, por exemplo, o trabalho interdisciplinar. Ao pensar no professor, entretanto, é importante atentarmos ao fato de que, para isso, faz-se necessário muito mais que uma formação. Como menciona Nóvoa (2017, p. 1.121), "tornar-se professor é transformar uma predisposição numa disposição pessoal. Precisamos de espaços e de tempos que permitam um trabalho de autoconhecimento, de autoconstrução". Como ele elucida, é importante que, no processo de formação, o professor se reconheça em tal lugar de educador e é importante que haja espaços para essa discussão. Desse modo, precisamos de um acompanhamento, de uma reflexão sobre a profissão desde o primeiro dia de aula, que também ajudam a combater os fenômenos de evasão e, mais tarde, de "desmoralização" e de "mal-estar" dos professores (NÓVOA, 2017).

Na concepção de Nóvoa (2017), nas profissões do humano há uma ligação forte entre as dimensões pessoais e as dimensões profissionais. No caso da docência entre aquilo que somos e a maneira como ensinamos. Isso se dá pelo fato de que, em muitos casos, o educador, por vezes, entra em conflito com seus conhecimentos/crenças pessoais, com aquilo que precisa ensinar e com a forma que precisa ensinar. Essas situa- 
ções, no entanto, estão interligadas; por isso, é relevante compreender que o professor precisa ser mediador do conhecimento. Nessa mediação, é importante que ele tenha um olhar atrelado ao seu conhecimento, mas também a que sujeito ele terá de ensinar.

Diante disso, não há professores iguais; cada um faz uso de metodologias específicas e distintas em suas aulas, dependendo dos conteúdos que ensina. Assim, com modos singulares de conduzir o processo de ensino, cada um tem sua maneira própria de ser professor, a sua composição pedagógica, processo que "[..] faz-se com os outros e valoriza o conhecimento profissional docente, a que alguns chamam tato pedagógico ou ação sensata ou outros nomes" (NÓVOA, 2017, p. 1.125).

Sobre o conhecimento das disciplinas, é importante assinalar dois pontos para bem compreender a sua função numa formação profissional. Por um lado, um professor precisa ter um conhecimento mais orgânico, historicizado, contextualizado e compreensivo da disciplina que vai ensinar do que o especialista dessa mesma disciplina. Por outro lado, a formação de professores não pode deixar de acompanhar a evolução da ciência e das suas modalidades de convergência. "Em tempos do digital, a visão enciclopédica das disciplinas vem sendo naturalmente substituída por formas mais exigentes e problematizadoras de aquisição do conhecimento" (NÓVOA, 2017, p. 1.125).

Ainda, segundo o autor, a entrada de um professor despreparado na sala de aula coloca-o perante uma série de relações externas, marcadas pelo comportamento dos seus alunos e por reações involuntárias. Para ele, esse é o primeiro gênero de conhecimento. Ao compreender o ritmo da sala de aula, as relações que a compõem, o professor acede ao segundo gênero de conhecimento. A capacidade de compreender a "essência" do ensino e sobre ela falar, representa o terceiro gênero de conhecimento. A segunda aproximação vem de um conceito antigo, como destaca Nóvoa (2017). O tato pedagógico refere-se a compreender o senso, a inteligência ou a compostura pedagógica que definem os professores que, mais naturalmente, exercem a sua ação. A última aproximação refere-se à ideia de discernimento, isto é, à capacidade de julgar e de decidir no dia a dia profissional.

No contexto do Proeja reconhecemos esse tato pedagógico nos dizeres dos sujeitos $1,2,3,5,6,7$ e 8, ao se referirem à atuação dos seus professores e à organização do ensino por áreas do conhecimento. Em síntese, as expressões "bem avaliado, explicado, interativo" e "interdisciplinar (tudo está relacionado)" estão consoantes à preocupação de Nóvoa (2017). Dessa forma, ratificamos que, além de um conhecimento de disciplinas, é necessário que o professor compreenda a "essência" do ensino. Como o autor menciona, "ser professor não é apenas lidar com o conhecimento, é lidar com o conhecimento em situações de relação humana" (NÓVOA, 2017, p. 1.127).

Constituída por sujeitos que se desenvolvem em meio a, e com relações humanas, o Proeja está passível de promover possibilidades de superação de modelos curriculares tradicionais, disciplinares e rígidos. A desconstrução e construção de modelos curriculares e metodológicos, observando as necessidades de contextualização ante a realidade do educando, promovem a ressignificação de seu cotidiano. Por fim, insistimos em destacar o Documento Base (BRASIL, 2007) quanto à defesa de que a concepção de des- 
construção curricular permite a abordagem de conteúdos e práticas inter e transdisciplinares, a utilização de metodologias dinâmicas, promovendo a valorização dos saberes adquiridos em espaços de educação não formal, além do respeito à diversidade.

\section{Processo de Aprendizagem do Jovem e do Adulto}

O ensinar é coletivo, mas o aprender e a internalização do conhecimento são individuais, ocorrendo, conforme a concepção histórico-cultural de Vygotsky (1998, p. 75), em dois planos: "interpsicológico (entre as pessoas, no plano social) e intrapsicológico (internalização do conhecimento, individual)". Dessa perspectiva, como é possível definir a aprendizagem de um sujeito jovem e adulto no contexto da EJA e do Proeja? Ao encontro da perspectiva de Vygotsky, e dela se valendo, Oliveira (2004, p. 214) afirma que o desenvolvimento ocorre de modo individual "no interior de uma determinada situação histórico-cultural, que fornece aos sujeitos, e com eles constantemente reelabora, conteúdos culturais, artefatos materiais e simbólicos, interpretações, significados, modos de agir, de pensar, de sentir". Em elaborações singulares, Oliveira (2004) caracteriza o desenvolvimento dos sujeitos jovens e adultos por meio de ciclos de vida.

Mediante elaborações como a de ciclos de vida dessa autora e pela concepção histórico-cultural, é que reconhecemos desenvolvimento, sinteticamente, como processo de transformação que ocorre ao longo da vida dos indivíduos, relacionado a um conjunto complexo de fatores. A imensa multiplicidade de conquistas psicológicas que acontece durante a vida de cada sujeito, entretanto, gera uma complexa configuração de processos de desenvolvimento que será absolutamente singular para cada um (OLIVEIRA, 2004). Nesse viés, Sanceverino (2016) ratifica que o espaço pedagógico da EJA é um espaço fértil de possibilidades de articulação de outras realidades culturais, outros saberes, assim como a vida é uma rede de relações dialógicas que se articula indefinidamente com saberes complexos, um encontro de homens e mulheres no qual o conhecimento só faz sentido quando é voltado para a construção do diálogo permanente.

Na esteira de Oliveira (2004) e Sanceverino (2016), reconhecemos o Proeja como espaço fértil de possibilidades de articulação de diferentes realidades e com sujeitos cujos ciclos de vida evidenciam estreitas relações com o mundo do trabalho. Se configurados como espaços-tempos pautados pelo reconhecimento da existência de vivências pessoais e profissionais e, somado a isso, como uma proposta pedagógica pensada por meio de um currículo por áreas do conhecimento, o Proeja pode cumprir com sua função sociocultural: subsidiar o direito à educação, desde o acesso até a permanência, e, em especial, mediar o desenvolvimento psicológico, "processo de constante transformação e de geração de singularidades" (OLIVEIRA, 2004).

Os processos de ensino a jovens e adultos no contexto da EJA e da Educação Profissional, contudo, não podem ser pensados fora do emaranhado das várias situações que ocorrem diariamente na vida deles. Conforme Oliveira (2004), ser adulto, trabalhador, estudante, pai (ou mãe) de família, participante de sindicato ou membro de grupo religioso, são condições que, em diferentes combinações e com diversos significados, constituem formas peculiares de construção de conhecimento e de aprendizagem. 
Nesse processo, valorizam-se e legitimam-se saberes que jovens e adultos construíram em sua trajetória de vida, considerando-se a diversidade dos sujeitos e a inconclusão humana, princípios básicos de qualquer ação educativa, não persistindo a ideia de idade apropriada, tampouco a existência de um único lugar de aprendizagem (BARCELOS, 2014).

Ao encontro dessa perspectiva de considerar e respeitar as condições pessoais e profissionais dos sujeitos jovens e adultos, está o destaque de um dos participantes da pesquisa: "condição de tempo (menor) conclui dois em um em menos tempo". Outro estudante destaca que é "bom e interessante, dá condições de melhorar". Nesse sentido, consoante Barcelos (2014), oferecer uma educação de qualidade a sujeitos jovens e adultos implica conhecer sua realidade e reconhecer necessidades, possibilidades e aspirações, incluindo-os nesse processo.

Nessa perspectiva, valemo-nos da compreensão de Arroyo (2017), ao destacar os "passageiros da noite", sujeitos jovens e adultos que buscam o Proeja e "viajam" de segunda a sexta, como sujeitos que trazem consigo esperança quanto à conquista de uma vida mais digna e mais humana por meio da conclusão dos estudos. Como problematiza o autor, entretanto, esses sujeitos sofrem com a ausência de identidade e, em nosso ponto de vista, esta é uma das potencialidades do Proeja: subsidiar o reconhecimento e a assunção identitária, histórica e socialmente situada.

\section{Relação dos Conhecimentos da Área Básica e da Área Técnica}

Como já destacado neste texto, o Curso Técnico Integrado em Edificações Proeja possui uma proposta de organização curricular embasada nas concepções do currículo integrado, e tem como premissa a articulação entre a formação acadêmica e o mundo do trabalho. Ratificamos também que a intenção é possibilitar o estabelecimento de relações entre os conhecimentos construídos nas diferentes disciplinas do curso e a prática real de trabalho.

Para tanto, a flexibilização curricular e a ampliação do diálogo entre as diferentes áreas de formação são fundamentais (SANTA MARIA, 2014) para essa articulação, correlata ao que Di Pierro e Haddad (2015, p. 211) destacam como política de intersecção:

A criação do Proeja em 2006 foi o principal ponto de intersecção entre as políticas federais de educação profissional e de EJA dos anos 2000 e, embora tivesse pequeno porte e não ocupasse lugar de destaque na agenda da política nacional, o Programa mobilizou parcela significativa dos pesquisadores e educadores da EJA, que se engajaram na docência, formulação dos currículos, formação de educadores e monitoramento. Foi nessa ambiência que a Lei n. 11.741 de 2008 alterou o capítulo da LDBEN sobre Educação Profissional e Tecnológica e modificou o Art. 37, para nele inserir um parágrafo estabelecendo que a EJA deva articular-se preferencialmente à educação profissional.

Fruto de uma articulação prevista em lei, o Proeja é um espaço-tempo singular para a constituição docente no curso de Licenciatura em Ciências Biológicas, especialmente quando se trata de um currículo que tem a formação geral organizada em áreas 
de estudo. Ao encontro desse pressuposto, há conhecimentos que "dialogam", o que é percebido pelos sujeitos 5, 7 e 9. Em suas falas, explicitam que "todas as matérias são importantes", tendo cada uma sua peculiaridade e direção específica.

Ao encontro da concepção de ensino integrado, outro ponto citado pelos sujeitos participantes da pesquisa trata da organização curricular, a qual, para eles, é feita de modo que contemple tanto a formação básica quanto a teórica, tendo "boa distribuição, proporciona bom conhecimento de ambos". Tal afirmação nos permite pensar ainda sobre o "espaço de conhecimento" que se estabelece, mas, por outro lado, mesmo que assim reconheçam (esse espaço de conhecimento e que todos os conhecimentos são importantes), é preciso pensar sobre a relação que existe entre a parte da área básica e a técnica. Segundo os sujeitos que foram entrevistados, há uma "sobreposição" de carga horária sem haver, no entanto, indicativo de qual "sobreposição" quanto à contribuição de ambas na formação. Mesmo que de forma indireta, tais compreensões permitem a inferência de que se trata do reconhecimento da oferta de uma proposta de Ensino Médio Integrado, pautado pela Educação Integral. Conforme Pacheco (2020, p. 12),

Educação Integral é princípio educativo básico e identidade fundante dos IFs. Supera a Educação tradicional que propõe educação geral de qualidade para as classes dominantes e formação profissional para os trabalhadores, separando teoria e prática, ciência e tecnologia, pensar e fazer. O Ensino Médio Integrado (EMEI) é a expressão curricular da Educação Integral, possibilitando uma formação que contemple todas as dimensões do ser humano, não fragmentando a compreensão dos fenômenos naturais e sociais, articulando os currículos com as práticas sociais, superando a simples aquisição de habilidades instrumentais, sem a compreensão de seu papel no processo produtivo. Busca superar a contradição entre trabalho intelectual (teoria|ciência) e trabalho manual (técnicalexecução) e criar condições para que o educando seja capaz de produzir ciência, tecnologia e arte, integrando o saber acadêmico com o saber popular.

Ao encontro da Educação Integral, podem ser citadas outras atividades que vão além da sala de aula ao longo do curso, como a Prática Profissional Integrada (PPI). No IFFar, a PPI ${ }^{4}$ é um dos espaços-tempos no qual se busca subsidiar um itinerário formativo pautado pela politecnia, pela formação integral, omnilateral, a interdisciplinaridade, integrando os núcleos da organização curricular. No Proeja, esse espaço-tempo é essencial se considerar-se que seus sujeitos são jovens e adultos inseridos no mundo do trabalho e das relações interpessoais (OLIVEIRA, 2004).

Temos ciência que o currículo integrado, ao não ser mera postura metodológica, diz respeito a uma concepção teórica que, epistemologicamente, se refere a um projeto de sociedade arraigado no reconhecimento e na necessidade de contraposição das desigualdades sociais e de lutas de classes. Destacamos, nesse sentido, nossa compreensão 
a partir da ATD realizada no presente estudo. A integração curricular como princípio, somado à relação teoria e prática e ao trabalho como princípio educativo em contexto de politecnia, corresponde ao esforço institucional do IFFar de promover Educação Profissional, Básica e Tecnológica, ao encontro do currículo integrado.

\section{COMPREENSÕES FINAIS}

A partir deste estudo, foi possível compreendermos, além da organização de um currículo que busca integrar educação básica e profissional, questões constitutivas dos sujeitos que compõem a EJA, em especial quanto aos processos de aprendizagem e desenvolvimento. Como todo indivíduo em processo de escolarização, os estudantes do Proeja possuem modos de pensar, sentir e agir únicos e singulares (OLIVEIRA, 2004). Dada essa diversidade, compreendemos algumas condições para o exercício profissional da docência na modalidade. Em síntese, (re)conhecer as trajetórias de vida diferentes, de acordo com o contexto em que estão inseridos, permite ao professor planejar sua prática de forma a não somente promover a ampliação de conhecimentos anteriores e espontâneos, mas de espaços-tempos nos quais os jovens e adultos possam (res) significá-los em perspectiva de formação humana e integral. O que, todavia, compreendemos sobre esses pressupostos no contexto da educação básica integrada à educação profissional? O que pensamos a partir de respostas breves de um pequeno grupo de sujeitos jovens e adultos quando questionados sobre seus pensares?

Guiadas por esta provocação, sem a pretensão de interpretar tais respostas de forma a desvelar verdades, o processo de ATD permitiu-nos a retomada de conceitos que visualizamos como princípios didático-pedagógicos do Proeja. Estes são evidenciados de maneira recorrente, tanto nos documentos institucionais quanto nas legislações nacionais que versam sobre a Educação Básica e a Educação Profissional: educação integral, formação humana e, para sua concretude, relações teórico-práticas, tendo como enfoque a ampliação da capacidade de jovens e adultos quanto à compreensão da realidade específica em que se situam. Relacionar a realidade histórico-cultural à totalidade social configura-se como processo que favorece esses sujeitos para que se reconheçam identitariamente, tanto em relação ao mundo do trabalho quanto em suas vivências cotidianas em meio aos diferentes grupos e instituições sociais das quais fazem parte, transformando-se e transformando-as.

Salientamos, então, o cuidado com os processos de pensar atenciosamente no que se refere ao modo como os jovens e adultos aprendem, o que demanda espaços e tempos para que os docentes transformem a predisposição em disposição para autotransformar-se (NÓVOA, 2017). A premissa de integração entre a formação para a Educação Profissional e a formação para o Ensino Médio na modalidade EJA, sendo organizada por áreas do saber, em nosso ponto de vista qualifica os sujeitos jovens e adultos para o mundo do trabalho, na medida em que subsidia a assunção de identidades. Inseridos e interagindo em propostas como as descritas no presente texto, os estudantes de Proeja vivenciam a possibilidade de reconhecerem-se sujeitos de conhecimento, sujeitos sociais e em desenvolvimento. 


\section{REFERÊNCIAS}

ARROYO, Miguel González. Passageiros da noite: do trabalho para a EJA: itinerários pelo direito a uma vida justa. Petrópolis: Vozes, 2017.

BARCELOS, Luciana Bandeira. O que é qualidade na Educação de Jovens e Adultos? Educação \& Realidade, Porto Alegre, v. 39, n. 2, p. 487-509, abr./jun. 2014. Disponível em: http://www.ufrgs.br/edu_realidade. Acesso em: 12 nov. 2019.

BRASIL. Resumo Técnico: Censo da Educação Básica 2018. Brasília: Instituto Nacional de Estudos e Pesquisas Educacionais Anísio Teixeira, 2019a.

BRASIL. Anuário Brasileiro da Educação Básica. 2019b. Disponível em: https://www.todospelaeducacao. org.br/_uploads/_posts/302.pdf. Acesso em: 12 jan. 2020.

BRASIL. Lei de Diretrizes e Bases da Educação Nacional. Lei n 13.796, de 2019c.

BRASIL. Ministério da Educação. Resolução CNE no 02/2019 - Define as Diretrizes Curriculares Nacionais para a Formação Inicial de Professores para a Educação Básica e institui a Base Nacional Comum para a Formação Inicial de Professores da Educação Básica. Brasília: MEC, Conselho Nacional de Educação, Secretaria Executiva, 2019d.

BRASIL. Lei no 11.892, de 29 de dezembro de 2008. Institui a Rede Federal de Educação Profissional, Científica e Tecnológica, cria os Institutos Federais de Educação, Ciência e Tecnologia, e dá outras providências. Diário Oficial da União, Brasília, 30 dez. 2008.

BRASIL. Programa Nacional de Integração da Educação Profissional com a Educação Básica na Modalidade de Educação de Jovens e Adultos. Documento base. Brasília, ago. 2007.

BRASIL. Ministério da Educação. Decreto $n^{\circ}$ 5.840/06. Institui, no âmbito federal, o Programa Nacional de Integração da Educação Profissional com a Educação Básica na Modalidade de Educação de Jovens e Adultos - Proeja. Brasília: MEC, 2006.

BRASIL. Ministério da Educação. Decreto $n^{\circ}$ 5.154/04. Regulamenta o $§ 2 \cong$ do art. 36 e os arts. 39 a 41 da Lei $n \cong 9.394$, de 20 de dezembro de 1996, que estabelece as diretrizes e bases da educação nacional, e dá outras providências. Brasília: MEC, 2004.

BRASIL. Ministério da Educação. Resolução CNE/CP no 02/2015 - Define as Diretrizes Curriculares Nacionais para a formação inicial em nível superior (cursos de licenciatura, cursos de formação pedagógica para graduados e cursos de segunda licenciatura) e para a formação continuada. Brasília: MEC; Conselho Nacional de Educação; Conselho Pleno, 2015.

BRASIL, Ministério da Educação. Resolução CNE/CEB no 06/2012 - Define Diretrizes Curriculares Nacionais para a Educação Profissional Técnica de Nível Médio. Brasília: MEC; Conselho Nacional de Educação; Câmara de Educação Básica, 2012.

FRIGOTTO, Gaudêncio; ARAÚJO, Ronaldo Marcos de Lima. Práticas pedagógicas e ensino integrado. Revista Educação em Questão, Natal, v. 52, n. 38, p. 61-80, maio/ago. 2015.

DI PIERRO, Maria Clara; HADDAD, Sérgio. Transformações nas Políticas de Educação de Jovens e Adultos no Brasil no início do terceiro milênio: uma análise das agendas nacional e internacional. Cadernos Cedes, Campinas, v. 35, n. 96, p. 197-217, maio/ago. 2015. Disponível em: http://dx.doi.org/10.1590/CC010132622015723758. Acesso em: 20 nov. 2019.

MOHR, Ana Lúcia Moreira; FONTOURA, ANA Rita Kraemer da; WISNIEWSKI, Rudião Rafael; MESSER, Sylvia. Currículo integrado no PROEJA: dos projetos integradores à organização curricular por áreas do conhecimento. In: HAMES, Clarinês; ZANON, Basso; PANSERA-DE-ARAÚJO, Maria Cristina. (org.). Currículo integrado, educação e trabalho: saberes e fazeres em interlocução. Ijuí: Editora Unijuí, 2016. p. 183-198. NóVOA, António Sampaio. Firmar a posição como professor, afirmar a profissão docente. Cadernos de Pesquisa, v. 47, n. 166, p. 1.106-1.133, out./dez. 2017.

OLIVEIRA, Marta Kohl de. Ciclos de vida: algumas questões sobre a psicologia do adulto. Educação e Pesquisa, São Paulo, v. 30, n. 2, p. 211-229, maio/ago. 2004.

PACHECO, Eliezer. Desvendando os Institutos Federais: identidade e objetivos. Educação Profissional $e$ Tecnológica em Revista, Vitória, v. 4, n. 1, p. 4-22, 2020.

PAIVA, Jane; HADDAD, Sérgio; SOARES, Leôncio José Gomes. Pesquisa em educação de jovens e adultos: memórias e ações na constituição do direito à educação para todos. Revista Brasileira de Educação, v. 24, p.1-25, 2019. Disponível em: http://dx.doi.org/10.1590/S1413-24782019240050. Acesso em: 30 nov. 2019. 


\section{\& Contexto}

Currículo Integrado e Formação Profissional no Proeja:

Concepções Acerca do Ensino Por Área do Conhecimento

SANCEVERINO, Adriana Regina. Mediação pedagógica na Educação de Jovens e Adultos: exigência existencial e política do diálogo como fundamento da prática. Revista Brasileira de Educação, v. 21. n. 65, p. 455-475, abr./jun. 2016.

SANTA MARIA. Instituto Federal. Plano de Desenvolvimento Institucional-PDI 2019-2026. Santa Maria: Instituto Federal, 2019.

SANTA MARIA. Instituto Federal. Projeto Pedagógico de Curso. Santa Maria: Instituto Federal, 2014.

SOUZA, Robson Simplício de; GALIAZZI, Maria do Carmo. Compreensões acerca da hermenêutica na análise Textual Discursiva: marcas teórico-metodológicas à investigação. Contexto e Educação, ljuí, ano 31, n. 100, p. 33-35, set./dez. 2016.

VIGOTSKY, L. S. A formação social da mente: o desenvolvimento dos processos psicológicos superiores. 6. ed. São Paulo: Martins Fontes, 1998. 